\title{
Impact of morbidity on care need increase and mortality in nursing homes: a retrospective longitudinal study using administrative claims data
}

\author{
Katrin C. Reber ${ }^{1}$, Ivonne Lindlbauer ${ }^{1}$, Claudia Schulz ${ }^{1}$, Kilian Rapp² and Hans-Helmut König ${ }^{1 *}$ (D)
}

\begin{abstract}
Background: A growing number of older people are care dependent and live in nursing homes, which accounts for the majority of long-term-care spending. Specific medical conditions and resident characteristics may serve as risk factors predicting negative health outcomes. We investigated the association between the risk of increasing care need and chronic medical conditions among nursing home residents, allowing for the competing risk of mortality.

Methods: In this retrospective longitudinal study based on health insurance claims data, we investigated 20,485 older adults ( $\geq 65$ years) admitted to German nursing homes between April 2007 and March 2014 with care need level 1 or 2 (according to the three level classification of the German long-term care insurance). This classification is based on required daily time needed for assistance. The outcome was care level change. Medical conditions were determined according to 31 Charlson and Elixhauser conditions. Competing risks analyses were applied to identify chronic medical conditions associated with risk of care level change and mortality.

Results: The probability for care level change and mortality acted in opposite directions. Dementia was associated with increased probability of care level change compared to other conditions. Patients who had cancer, myocardial infarction, congestive heart failure, cardiac arrhythmias, renal failure, chronic pulmonary disease, weight loss, or recent hospitalization were more likely to die, as well as residents with paralysis and obesity when admitted with care level 2.

Conclusion: This paper identified risk groups of nursing home residents which are particularly prone to increasing care need or mortality. This enables focusing on these risk group to offer prevention or special treatment. Moreover, residents seemed to follow specific trajectories depending on their medical conditions. Some were more prone to increased care need while others had a high risk of mortality instead. Several conditions were neither related to increased care need nor mortality, e.g., valvular, cerebrovascular or liver disease, peripheral vascular disorder, blood loss anemia, depression, drug abuse and psychosis. Knowledge of functional status trajectories of residents over time after nursing home admission can help decision-makers when planning and preparing future care provision strategies (e.g., planning of staffing, physical equipment and financial resources).
\end{abstract}

Keywords: Care need, Competing risk, Long-term care, Mortality, Nursing home

\footnotetext{
* Correspondence: h.koenig@uke.de

'Department of Health Economics and Health Services Research, Hamburg Center for Health Economics, University Medical Center Hamburg-Eppendorf, Martinistr. 52, 20246 Hamburg, Germany

Full list of author information is available at the end of the article
}

(C) The Author(s). 2020 Open Access This article is licensed under a Creative Commons Attribution 4.0 International License, which permits use, sharing, adaptation, distribution and reproduction in any medium or format, as long as you give appropriate credit to the original author(s) and the source, provide a link to the Creative Commons licence, and indicate if changes were made. The images or other third party material in this article are included in the article's Creative Commons licence, unless indicated otherwise in a credit line to the material. If material is not included in the article's Creative Commons licence and your intended use is not permitted by statutory regulation or exceeds the permitted use, you will need to obtain permission directly from the copyright holder. To view a copy of this licence, visit http://creativecommons.org/licenses/by/4.0/. The Creative Commons Public Domain Dedication waiver (http://creativecommons.org/publicdomain/zero/1.0/) applies to the data made available in this article, unless otherwise stated in a credit line to the data. 


\section{Background}

Population aging is likely to be accompanied by an increasing demand for care as a larger number of older people with chronic illness, disabilities and severe functional limitations will be expected. According to recent model calculations, the number of dependent older adults with need for care will increase from 101 million in 2010 to 277 million in 2050 globally [1]. These projections suggest that the number of people needing longterm care in institutional settings (e.g., nursing homes) will rise considerably. In Germany, the percentage of institutionalized adults aged 65 years and older increased from $3.8 \%$ in 2010 to $4.1 \%$ in 2015 [2]. Of those who qualify for the benefits of the long-term care insurance, $23 \%$ between 65 and 80 years of age live in an institution, whereas the number is about one third for those aged 80 or older [3].

The older population partly lives in rural areas where, for a long time, family members have often taken on caregiving roles. However, living arrangements among older people and their families have been changing considerably over the past years. Due to the continuing outmigration of young people to urban areas spatial proximity to children (and other kin) decreases, and other options of caregiving services are required [4]. As a consequence, demand for nursing home care is likely to stay high or grow even further [5].

Functional decline, disability, and frailty entailed by advanced age are prevalent in the nursing home population. Regular monitoring of functional status after nursing home admission is regarded as a core measure informing the type and intensity of care needed. Although data are available on the functional status trajectory of community-dwelling older people, less is known regarding nursing home residents [6]. The functional status indicates frailty and dependency of nursing home residents on assistance to perform activities of daily living [7] (ADL). Care dependents may have to deal with impaired mobility, restricted ability to be alone, and reduced quality of life [8]. The care need of nursing home residents is determined by chronic diseases [9], which implies functional status as a proxy for the overall health status.

Moreover, knowledge about functional trajectories of nursing home residents and their care needs is important, as this requires anticipatory planning of care and management of resources [10]. Long-term care in institutional settings is expensive and accounts for the majority of long-term care spending [11, 12]. Projections reveal a continuing growth of public long-term care expenditures over the next decades [11, 13]. On average, OECD countries spent about $1.5 \%$ of their GDP on long-term care. In Germany, public expenditures on long-term care in general accounted for $1.4 \%$ of GDP in
2013, with expenditures on residential long-term care amounting to approx. 0.9-1\% of GDP $[14,15]$.

Several medical conditions and resident characteristics have been discussed to be potential risk factors predicting negative health outcomes like a worsened functional performance or mortality $[16,17]$. Such a deterioration of health status may be associated with a change in the care need (i.e., transition to a higher care need level). Identification of and information about the specific risk profile of older adults admitted to nursing homes is therefore crucial for health policy decision makers, nursing homes and families in order to allocate (financial) resources and to meet future care expenses.

In Germany, care recipients are compulsorily classified according to their care need by the long-term care insurance. To claim benefits from the long-term care insurance, people must need a daily minimum of assistance with basic ADL (washing, eating, toileting, or dressing) and instrumental ADL (preparing meals, shopping, cleaning, using the telephone, or moving within the community). The verification and assessment of care needs is performed by the medical service of the health insurance funds according to a standardized procedure. Depending on the amount of care required recipients are classified into one of three levels: care level 1 recipients need at least 45 min of basic care a day and at least $90 \mathrm{~min}$ in total of general help (ADL/instrumental ADL combined). Care level 2 and 3 recipients require assistance for at least 180 and $300 \mathrm{~min}$ a day for general help, of which a minimum of 120 and $240 \mathrm{~min}$ is dedicated to basic ADLs, respectively [18]. The categorization in one of the three levels of care can therefore be regarded as a surrogate of disability [19].

The aim of this study was to examine the association of a wide range of chronic medical conditions with risk of increasing care need in terms of care level change (to a higher level) among nursing home residents. Given that nursing home residents are highly susceptible to mortality [20] which may prevent them from care level change, mortality may alter the chance of care level change to occur [21]. Ignoring mortality may thus not give accurate estimates of risk of care level change [22, 23]. Therefore, we applied an estimation method that explicitly takes into account the competing risk of mortality.

\section{Methods}

\section{Data sources and study population}

Routinely collected health insurance claims data on age, sex, in- and outpatient diagnoses, hospitalization stay, status of care level, nursing home residency, and date of death, if applicable, were used. All data were provided by the social insurance for agriculture, forestry, and 
horticulture, which mainly covers agriculturists and their families.

Within the German long-term care system, the need for care is described by three care levels that take account for the support and intensity required in ADL. Care level 1 is intended for mild dependency, care level 2 for moderate dependency and care level 3 reflects severe dependency. We considered individuals admitted to a nursing home with care level 1 or 2 between April 2007 and March 2014 who were 65 years or older at admission. Our outcome of interest was care level change to a higher level. Therefore, we excluded individuals assigned to care level 3 prior to nursing home admission because they could not move to a higher care level.

\section{Outcome variable}

The primary outcome measure was time from nursing home admission to care level change (to a higher care level). Mortality was treated as competing event. Individuals were followed from the date of nursing home admission (baseline). For risk estimation, the time to a care level change was calculated from baseline to either date of care level change (event of interest) or mortality (competing event). Individuals alive without care level change were censored, as were those who left nursing homes.

\section{Study variables}

Baseline characteristics recorded at the time of nursing home admission included age and sex. Age was classified in 10-year age groups in order to provide a sufficient number of observations per age group. We also observed whether an individual was hospitalized within 60 days prior to nursing home admission because it has been demonstrated that such a proximal event can have deleterious effects on health outcomes and may be predictive of (further) functional decline and dependence in older adults [24, 25]. For each individual the presence or absence of several medical conditions (at baseline) was determined. This selection of medical conditions was based on a previously described combination of conditions from the Charlson Index [26] and the Elixhauser comorbidity system $[27,28]$. Inpatient and outpatient diagnoses based on the International Classification of Diseases, 10th revision (ICD-10) recorded up to 12 months prior to nursing home admission (plus an additional 14-days grace period after nursing home admission) were considered in the calculations. A final set of 31 medical conditions was included in the analyses. However, the prevalence of HIV in our sample was negligible and therefore removed.

\section{Statistical analysis}

Descriptive statistics were used to summarize the baseline characteristics of our study sample. The study variables at baseline were compared according to care level at admission. Cumulative incidence functions were used to depict the absolute risk of the event of interest, care level change, and the competing event, mortality, over time.

For multivariate modelling we applied the subdistribution hazard model proposed by Fine and Gray [29]. Mortality during follow-up was treated as competing risk. In the Fine and Gray model, individuals who died prior to experiencing a care level change were not censored but were kept in the risk set. The assumption of proportional hazards was evaluated by visual inspection of Schoenfeld-type residuals and by including interaction terms between covariates and time. No violation of this assumption was found for the medical conditions covariates.

Models were stratified according to care level at admission and adjusted for age, sex and having been hospitalized during the 60 days prior to nursing home admission (yes/no). As health insurance claims data usually comprise a high number of observations, a $p$-value less than .01 was considered statistically significant [30]. Data analyses were performed using SAS, version 9.3 (SAS Institute, Inc., Cary, NC) and the "pshreg" macro [31].

\section{Results}

\section{Sample characteristics}

The study population consisted of 20,485 individuals who met our inclusion criteria, out of which 10,048 (49.1\%) were admitted to a nursing home with care level 1 and 10,437 (50.9\%) with care level 2. Those with care level 1 had a mean age of 83.8 (SD: 6.3) years, and 63.3\% were female. Individuals admitted with care level 2 were, on average, 84.1 years (SD: 6.5 ) old, and $59.8 \%$ were female. In total, 7575 nursing home residents experienced an increase of care need (4962 residents changed from care level 1 to a higher care level, i.e., care level 2 or 3, and 2613 residents changed from care level 2 to care level 3), 7860 residents died, and 5050 residents were censored. The median time to care level change was 751 days (minimum 2 days, maximum 3255 days).

Of the 10,048 individuals admitted with care level 1 , $56.1 \%$ had a hospital stay within 60 days before nursing home admission, and of the 10,437 individuals admitted with care level 2, the proportion was $57.8 \%$. For individuals admitted with care level 1 , most prevalent medical conditions present at baseline were hypertension (78.0\%), congestive heart failure (48.2\%), dementia (42.1\%), cardiac arrhythmias (37.2\%), and cerebrovascular disease (32.1\%). Figures were similar for those admitted with care level 2, e.g. hypertension (76.6\%) was most 
prevalent followed by dementia (50.8\%), congestive heart failure (49.9\%), cerebrovascular disease $(41.3 \%)$, and cardiac arrhythmias (38.6\%) (Table 1).

Cumulative incidence curves for care need increase and mortality are shown in Fig. 1.

Fine and Gray models were fitted for care need increase and mortality. We regressed the hazard of care need increase and mortality (the competing event), respectively, on the risk factors described above. In Table 2, the estimated subdistribution hazard ratios (sHR) and their corresponding confidence intervals (CI) are shown.

\section{Cumulative incidence of care level change and mortality}

Figure 1 provides the cumulative incidence curves for both possible outcomes, care level change and mortality, considering competing risks. The cumulative incidence of care level change by year four was $51.1 \%$ (95\% CI 50.4-52.7) for individuals admitted with care level 1 (Fig. 1a) whereas 27.9\% (95\% CI 27.0-28.9) died. For those admitted with care level 2 (Fig. 1b) the cumulative incidence of a care level change by year four was $27.0 \%$ (95\% CI 26.0-28.0). The cumulative incidence of mortality by year four approached $57.8 \%$ (95\% CI 56.7-58.9).

\section{Results of the subdistribution hazard model for care level change}

Multivariate competing risk analysis, adjusting for age, sex and prior hospitalization, showed that residents with metastatic cancer (sHR 0.67, 95\% CI 0.54-0.83), myocardial infarction (sHR $0.81,95 \%$ CI $0.70-0.92$ ) or congestive heart failure (sHR 0.93, 95\% CI 0.87-0.98) were more likely to keep their level of care need when admitted to a nursing home with care level 1 compared to residents without the specific medical condition. Residents admitted with care level 2 who had metastatic cancer (sHR 0.44, 95\% CI 0.32-0.59), any tumor (sHR 0.72, 95\% CI 0.63-0.82), or congestive heart failure (sHR 0.83, 95\% CI $0.77-0.90$ ) also had a decreased probability. In contrast, dementia significantly increased the probability of care need increase, regardless of a resident's care level at admission (care level 1: sHR 1.43, 95\% CI 1.36-1.51; care level 2: sHR 1.74, 95\% CI 1.60-1.89). Remaining medical conditions did not achieve the threshold for statistical significance.

\section{Results of the subdistribution hazard model for the competing risk (mortality)}

Regardless of residents' care level upon admission, when having metastatic cancer (care level 1: sHR 2.45, 95\% CI 2.06-2.92; care level 2: sHR 2.27, 95\% CI 1.99-2.58), any tumor (care level 1: sHR 1.44, 95\% CI 1.30-1.60; care level 2: sHR 1.50, 95\% CI 1.39-1.62), myocardial infarction (care level 1: sHR 1.33, 95\% CI 1.14-1.55; care level 2: sHR 1.29, 95\% CI 1.15-1.44), and congestive heart failure (care level 1: sHR 1.22; 95\% CI 1.12-1.33; care level 2: sHR 1.17; 95\% CI 1.11-1.25), residents were more likely to die. Other conditions associated with mortality were cardiac arrhythmias, chronic pulmonary disease (COPD), renal failure, and weight loss. In contrast, residents with dementia were less likely to die when admitted with both care level 1 and 2 (care level 1: sHR 0.73; 95\% CI 0.67-0.80; care level 2: sHR 0.73; 95\% CI 0.69-0.78). Residents admitted with care level 2 with obesity or paralysis also showed a lower risk of mortality. Remaining medical conditions did not achieve the threshold for statistical significance (Table 2).

Furthermore, residents of older age (care level 1: sHR 1.41; 95\% CI 1.31-1.52; care level 2: sHR 1.26; 95\% CI $1.20-1.32$ ) and with a hospital stay prior to nursing home admission (care level 1: sHR 1.48; 95\% CI 1.361.61; care level 2: sHR 1.43; 95\% CI 1.35-1.52) were more likely to die, and females (care level 1: sHR 0.76; 95\% CI 0.69-0.82; care level 2: sHR 0.85; 95\% CI 0.80$0.90)$ were less likely to die.

\section{Discussion}

To analyze the association of the risk of care need increase in terms of care level change and a wide range of medical conditions among nursing home residents, we used health insurance claims data of more than 20,000 individuals admitted to a nursing home between 2007 and 2014. We considered medical conditions based on conditions included in the Charlson Index and the Elixhauser comorbidity system and designed specifically for use with administrative data [28]. As this population is particularly vulnerable to the competing risk of mortality, we employed models that explicitly allow considering this competing event.

We found that in this large nursing home population, after controlling for age, sex and hospital stay prior to nursing home admission, residents with dementia were more likely to sustain a care need increase. In contrast, residents with the chronic medical conditions cancer, congestive heart failure, and myocardial infarction were less likely to sustain a care need increase. Patients with these conditions were also found to be more likely to die, in addition to having any tumor, renal failure, COPD, and weight loss as well as paralysis and obesity when admitted with care level 2. Though our findings seem quite robust, given the large study sample, several medical conditions for which one might have expected an effect, were neither particularly related to care need increase nor mortality (e.g., diabetes, cerebrovascular disease). Also prior studies have described mixed results for e.g., diabetes or cerebrovascular disease regarding their association with survival in nursing homes [17, 32, 33]. It appeared that individuals with these conditions are less predictable as regards their functional 
Table 1 Resident characteristics according to care level at admission

\begin{tabular}{|c|c|c|c|c|}
\hline & \multicolumn{2}{|c|}{ Care level 1} & \multicolumn{2}{|c|}{ Care level 2} \\
\hline & \multicolumn{2}{|c|}{$n=10,048$} & \multicolumn{2}{|c|}{$n=10,437$} \\
\hline & \multicolumn{2}{|c|}{ N (\%) } & \multicolumn{2}{|c|}{$\mathrm{N}(\%)$} \\
\hline Age (in yrs) at nursing home admission, mean (SD) & 83.8 & $(6.3)$ & 84.1 & $(6.5)$ \\
\hline \multicolumn{5}{|l|}{ Age group (at baseline) } \\
\hline $65-<75$ yrs & 967 & $(9.6)$ & 994 & $(9.5)$ \\
\hline $75-<84$ yrs & 4444 & $(44.2)$ & 4514 & $(43.2)$ \\
\hline $85-<94$ yrs & 4371 & $(43.5)$ & 4483 & (43) \\
\hline $95+$ yrs & 266 & $(2.6)$ & 446 & $(4.3)$ \\
\hline Female & 6360 & $(63.3)$ & 6245 & $(59.8)$ \\
\hline \multicolumn{5}{|l|}{ Follow-up } \\
\hline Care level change & 4962 & $(49.4)$ & 2613 & $(25)$ \\
\hline Mortality & 2523 & $(25.1)$ & 5337 & $(51.1)$ \\
\hline \multicolumn{5}{|l|}{ Hospitalization stay (before baseline) } \\
\hline Up to 60 days & 5633 & $(56.1)$ & 6034 & $(57.8)$ \\
\hline \multicolumn{5}{|l|}{ Medical conditions (at baseline) } \\
\hline Alcohol abuse & 261 & $(2.6)$ & 221 & $(2.1)$ \\
\hline Any tumor & 1649 & $(16.4)$ & 1837 & $(17.6)$ \\
\hline Blood loss anemia & 113 & $(1.1)$ & 117 & $(1.1)$ \\
\hline Cardiac arrhythmias & 3736 & $(37.2)$ & 4026 & $(38.6)$ \\
\hline Cerebrovascular disease & 3226 & $(32.1)$ & 4313 & $(41.3)$ \\
\hline Chronic pulmonary disease & 2454 & $(24.4)$ & 2497 & $(23.9)$ \\
\hline Coagulopathy & 498 & $(5.0)$ & 477 & $(4.6)$ \\
\hline Complicated diabetes & 1398 & $(13.9)$ & 1506 & $(14.4)$ \\
\hline Congestive heart failure & 4848 & $(48.2)$ & 5212 & $(49.9)$ \\
\hline Deficiency anemias & 822 & $(8.2)$ & 846 & $(8.1)$ \\
\hline Dementia & 4235 & $(42.1)$ & 5303 & $(50.8)$ \\
\hline Depression & 3209 & $(31.9)$ & 3076 & $(29.5)$ \\
\hline Drug abuse & 103 & $(1.0)$ & 89 & $(0.9)$ \\
\hline Fluid and electrolyte disorders & 1730 & $(17.2)$ & 2284 & $(21.9)$ \\
\hline Hypertension & 7834 & $(78.0)$ & 7996 & (76.6) \\
\hline Hypothyroidism & 829 & $(8.3)$ & 864 & $(8.3)$ \\
\hline Liver disease & 934 & $(9.3)$ & 822 & $(7.9)$ \\
\hline Metastatic cancer & 397 & $(4.0)$ & 576 & $(5.5)$ \\
\hline Myocardial infarction & 581 & $(5.8)$ & 615 & $(5.9)$ \\
\hline Neurodegenerative disorders & 1456 & $(14.5)$ & 2305 & $(22.1)$ \\
\hline Obesity & 1127 & $(11.2)$ & 1153 & $(11.0)$ \\
\hline Paralysis & 573 & $(5.7)$ & 1379 & $(13.2)$ \\
\hline Peripheral vascular disorder & 1991 & $(19.8)$ & 2092 & $(20.0)$ \\
\hline Psychosis & 554 & $(5.5)$ & 555 & $(5.3)$ \\
\hline Pulmonary circulation disorders & 445 & $(4.4)$ & 443 & $(4.2)$ \\
\hline Renal failure & 2181 & $(21.7)$ & 2350 & $(22.5)$ \\
\hline Rheumatoid arthritis/collagen vascular diseases & 773 & $(7.7)$ & 792 & $(7.6)$ \\
\hline Ulcer disease & 344 & $(3.4)$ & 392 & (3.8) \\
\hline Uncomplicated diabetes & 3096 & (30.8) & 3373 & (32.3) \\
\hline
\end{tabular}


Table 1 Resident characteristics according to care level at admission (Continued)

\begin{tabular}{|c|c|c|c|c|}
\hline & \multicolumn{2}{|c|}{ Care level 1} & \multicolumn{2}{|c|}{ Care level 2} \\
\hline & \multicolumn{2}{|c|}{$n=10,048$} & \multicolumn{2}{|c|}{$n=10,437$} \\
\hline & \multicolumn{2}{|l|}{$\mathrm{N}(\%)$} & \multicolumn{2}{|c|}{$\mathrm{N}(\%)$} \\
\hline Valvular disease & 1464 & $(14.6)$ & 1448 & (13.9) \\
\hline Weight loss & 456 & $(4.5)$ & 570 & (5.5) \\
\hline
\end{tabular}

Unless otherwise indicated, values are expressed as numbers (percentages) of individuals yrs years, $S D$ standard deviation

trajectories. Possibly, the severity of the medical conditions of these individuals is more heterogeneous or there are further health-related issues which are not recorded in health insurance claims data.

Earlier research postulated that different trajectories of disability and decline exist when approaching the end of life $[34,35]$. Depending on prevalent medical conditions individuals may follow specific trajectories: terminally ill individuals (e.g., with cancer) or those with organ failure (e.g., heart failure, COPD) were more independent in their ADLs than frail people or those with dementia. These individuals may more likely die than sustain a care need increase, opposite to dementia patients. Terminally ill and organ failure individuals also showed a more modest or erratic functional decline until they reached the very last months of life [34]. Our results are quite in line with these earlier findings. There seem to exist those nursing home residents with cancer or congestive heart failure that fall into the terminally ill or organ failure group and are more likely to die than to change care level, those with dementia or other neurodegenerative who deteriorate further after nursing home placement requiring a care level change, and those that fall in none of these groups showing a less predictable pattern of decline.

Specifically, our results revealed that the probability for care level change and mortality worked in opposite directions. Dementia was identified to be the strongest risk factor associated with a care level change; while cancer was shown to exert the strongest effect on the cumulative incidence of mortality. Residents with dementia (compared to those without dementia) had a higher probability of experiencing a care level change and likely to remain long-term stayers. This may derive from the fact that in nursing homes dementia patients are more likely to sustain a care need increase and less likely to die compared to residents with other diseases and, therefore, are under risk for care need increase for a longer period of time, which would make it more likely to occur. In contrast, cancer decreased the probability of a care level change. Residents with cancer (compared to those without cancer) seem to have a quicker time to mortality and this competing event will occur before being able to encounter a care level change.

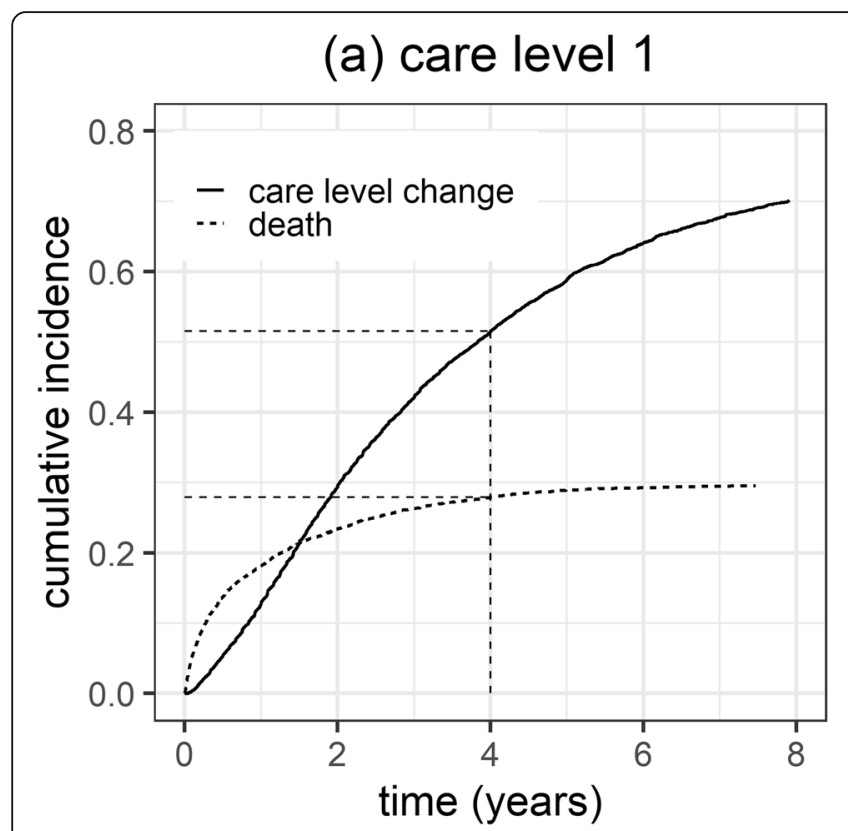

(b) care level 2

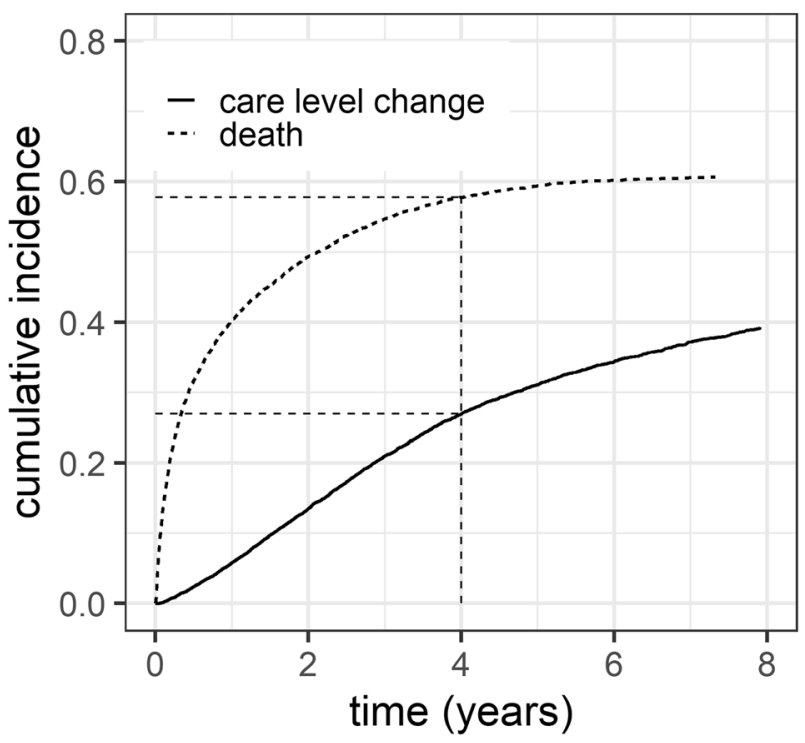

Fig. 1 Cumulative incidence curves of care level change and mortality for residents admitted with care level 1 (a) and care level 2 (b) 
Table 2 Results of the multivariate subdistribution hazard models for care level change and the competing event mortality, stratified by care level at admission

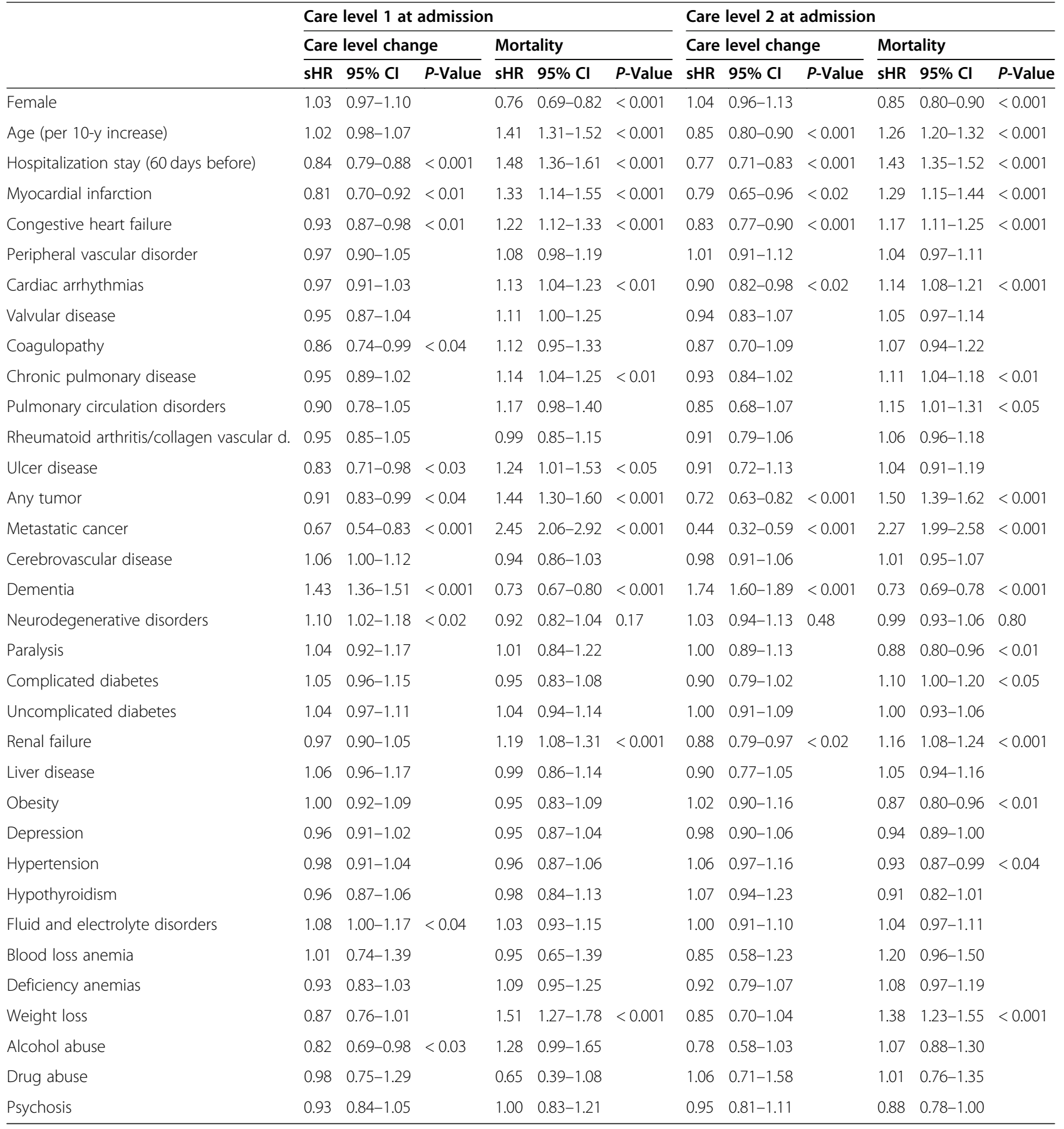

sHR subdistribution hazard ratio, $\mathrm{Cl}$ confidence interval, y year; collagen vascular d., collagen vascular disease

In support of our results, previous studies found dementia to be a clear predictor of ADL decline impeding physical function in various durations, e.g., due to psychological symptoms or acute illness related to dementia [36-38]. Earlier studies further showed an overall decline in ADL over time in long-stay nursing home residents with cognitive impairments. These elevated levels of physical impairments in turn necessitate greater support and assistance which translates in higher care burden and eventually in higher levels of care [38]. Results from two recent follow-up studies among nursing home residents in the Netherlands and Austria showed that dementia was predictive of an increase in care dependency over time $[39,40]$. Another study of nursing home 
residents with dementia indicated that the rate of decline in ADL functioning associated with dementia decreased over time [41]. It was further found that nursing home residents admitted with dementia had a lower risk of mortality compared to residents without dementia [42]. Moreover, some forms of dementia were associated with longer survival [42-44], however changes in care service use and the extent of care may vary with varying forms of dementia $[45,46]$.

The profile of adverse outcomes in residents admitted with dementia diverges from that of residents without dementia, suggesting that the two groups exhibit different disability patterns and thus care trajectories and distinct long-term care needs $[35,42]$. Using the nomenclature by Gill and colleagues [35], nursing home residents with dementia showed "persistent" or "progressive" patterns of disability (i.e. constant or slightly increasing disability) whereas in residents without dementia "accelerated" or "catastrophic" disability trajectories (i.e. faster or higher increase of disability) occurred. In these latter cases functional deterioration (resulting in death) happens rapidly precluding transfer to a higher care level. It is thus important for nursing home staff, residents as well as their relatives to take this into account. For the residents this may suggest a higher degree of dependence on nursing home staff or relatives as well as a higher amount of payment for care, and for the relatives it may possibly indicate more time needed for additional informal care. Nursing homes should consider the potentially increased resource utilization when preparing and planning resources for future care in terms of time or staff needed or environmental adaptions in order to address the special needs of residents with increased care need due to e.g., dementia.

Regarding cancer, a higher risk of mortality has been previously observed in the long-term care setting [17, 33, 36]. Similar to our findings, studies also found heart failure [17, 32, 33], chronic lung disease [17, 36], and weight loss [47-49] to be important risk factors for mortality in nursing home populations.

Possibly, there may be particular medical conditions that do not act individually but synergistically with other medical conditions. Together they may affect adverse outcomes like worsening of care level or mortality. Prior studies have pointed to the importance of synergistic effects of specific disease combinations. Some combinations were suggested to contribute to a decline in functional ability or higher mortality risk than one may expect when considering the effects of these diseases separately (e.g., arthritis and heart disease, depression and cognitive impairment) $[17,50,51]$. However, a study of mortality in a large population of institutionalized older people found only one (out of 36) disease combination (i.e., dementia and stroke) that emerged consistently as risk factor in their mortality risk prediction models [17]. The authors argued that disease severity rather than the mere presence of the disease could have been a more sensitive measure when analyzing synergistic effects. Alternatively, there could be an interaction between medical conditions prevalent upon nursing home admission and medical conditions that develop during the nursing home stay that affect adverse health outcomes [51]. We addressed this issue by investigating a large number of medical conditions and applying an appropriate model which considered changes over time.

Major strengths of our study are the large number of individuals admitted to a nursing home, a relatively long observation period that allowed us to examine long-term outcomes associated with several disease-related risk factors present upon nursing home admission, and an objective and well-established measure of medical conditions. We employed competing risk regression to study the association between several medical conditions and the risk of care need increase. We preferred this approach over a standard survival model because in nursing home populations, mortality may be a common competing risk, and ignoring such competing risks may lead to biased results [52]. In the presence of competing events, the traditional Kaplan-Meier method is inadequate to estimate the probability of the occurrence of an event (i.e., care level change or mortality) as it treats the competing event as a censored observation. KaplanMeier estimates the cumulative incidence in the absence of competing risks, which may be appropriate for censoring by loss to follow-up but less suitable for censoring by e.g., mortality. Consequently, Kaplan-Meier results in biases in the estimation of the probability of the event of interest [53]. In competing risk situations, the cumulative incidence function is therefore considered as more appropriate as it takes competing events into account when estimating the incidence, e.g., individuals who experience the competing event (mortality) first can no longer move on to experience the event of interest (care level change). We further chose the Fine and Gray model over the cause-specific hazard model as our primary interest was in predictive modelling. An appealing feature of the Fine and Gray model is that it allows estimating the effect of covariates on the cumulative incidence function of the event of interest [54]. When the primary interest is in risk prediction and prognosis, modelling absolute risk of the outcome, say care level change, rather than the instantaneous rate of the outcome in those who are event free has been suggested $[20,22]$. As our motivation was to predict the risk of care level change, we preferred to use the Fine and Gray model that directly offers estimated probabilities of the event of interest occurring over time, given an individual's risk factors. 
Our study has some limitations that should be considered when interpreting our results. First, we only had information available from administrative claims databases. Factors such as nursing staff quality or facility characteristics that might have affected our outcome could therefore not be controlled for. Second, identification of individuals' medical conditions was based on inpatient and outpatient diagnoses. While diagnostic misclassification should be low in the inpatient setting, the outpatient setting is prone to inaccurate diagnosis coding. Therefore, it is possible that some medical conditions (particularly those mainly diagnosed in an outpatient setting) were not or incorrectly specified. Third, we analyzed data between April 2007 and March 2014, which are already some years old. However, we intended to investigate care level change of residents during their nursing home stay, which requires a long follow-up. Furthermore, the German classification of care need was changed from three care levels to five care degrees in January 2017. In order to avoid biases, we refrained from investigating more recent data. Otherwise, no substantial changes to the regulation of nursing homes care were made. Therefore, the results of our analysis should still be valid and relevant. Fourth, we used data from the social insurance for agriculture, forestry, and horticulture. Thus, the results may not be representative for the German nursing home population as a whole. However, it may be considered representative of the nursing home population previously active in agriculture, horticulture or forestry who was therefore compulsorily insured at this social insurance. Due to the demographic shifts and rural-urban migration, this population will become increasingly important as rural areas remain disproportionally older. However, direct comparison of our findings with results from the literature is complicated due to different follow-up periods, different methodological approaches, different settings or care systems. Moreover, institutionalization and nursing home care depend on access to and availability of care facilities as well as on financial and human resources which may vary from country to country. This will restrict comparability and generalizations across health care systems.

\section{Conclusion}

Our competing risk analysis based on administrative claims data identified risk groups of nursing home residents which are particularly prone to increasing care need or mortality. Dementia was an important factor for care need increase regardless of a resident's care level at admission. Nursing home residents with dementia were more likely to experience a care need increase and more likely to live longer in a nursing home than residents without dementia. Thus, residents with dementia may remain long-stay residents in nursing homes compared to those without dementia. In contrast, residents with other prevalent diseases like metastatic cancer, any tumor, renal disease, COPD, myocardial infarction or congestive heart failure had a lower risk of care need increase, but a higher mortality risk compared to residents without these diseases. Several conditions were neither related to increased care need nor mortality, suggesting a less predictable pattern. These conditions were valvular, cerebrovascular or liver disease, peripheral vascular disorder, rheumatoid arthritis/collagen vascular disease, hypothyroidism, blood loss anemia, deficiency anemias, depression, psychosis, and drug abuse.

A better understanding of functional status trajectories over time after nursing home admission may help caregivers and clinicians to focus on these risk groups with regard to prevention or special treatment. Furthermore, it may help decision-makers when planning and preparing future care provision strategies (e.g., planning of staffing, physical equipment and financial resources).

\section{Abbreviations \\ ADL: Activities of daily living; Cl: Confidence interval; COPD: Chronic obstructive pulmonary disease; GDP: Gross domestic product; HIV: Human immunodeficiency virus; ICD-10: International Classification of Diseases, 10th revision; OECD: Organisation for Economic Co-operation and Development; SD: Standard deviation; SHR: Subdistribution hazard ratios; yrs: Years; y: Year; collagen vascular $\mathrm{d}$.: Collagen vascular disease}

\section{Acknowledgements}

The authors thank the social insurance for agriculture, forestry, and horticulture and especially Daniel Stöger and Andrea Grunz from the social insurance for agriculture, forestry and horticulture for granting access to the data and data support.

\section{Authors' contributions}

Study concept and design were developed by KCR, IL, CS and HHK. The acquisition of data was performed by KR, HHK and IL. Analysis of data was conducted by KCR, CS and IL. The interpretation of data was performed by KCR, IL, CS, KR and HHK. KCR drafted the manuscript. All authors read, critically revised and approved the final manuscript.

\section{Funding}

This work was supported by the German Federal Ministry of Education and Research (grant number 01EC1404D). The funders had no role in study design, data collection and analysis, decision to publish, or preparation of the manuscript. Open Access funding enabled and organized by Projekt DEAL.

\section{Availability of data and materials}

We declare that the data are owned by the German social insurance SVLFG. Since public deposition of the data would breach ethical and legal compliance, data are only available upon formal request from the SVLFG. To request the data please contact the institutional body of the SVLFG directly (poststelle@svlfg.de-mail.de). In order to fulfill the legal requirements to obtain that kind of data, researchers must conclude a contract with the SVLFG regarding data access. The licensee is permitted to use the data for the purpose of the research proposal only. Licensees are not allowed to pass the data to a third party, or to create Software or data bases with the exception of scientific publications. Moreover, the study has to be approved by the data protection officer both at the SVLFG and the research institute. 


\section{Ethics approval and consent to participate}

The present study was a retrospective, observational, non-interventional study and all data were fully anonymized, therefore approval by an Ethics Committee and informed consent of patients was not required.

\section{Consent for publication}

Not applicable.

\section{Competing interests}

The authors declare that they have no competing interests.

\section{Author details}

'Department of Health Economics and Health Services Research, Hamburg Center for Health Economics, University Medical Center Hamburg-Eppendorf, Martinistr. 52, 20246 Hamburg, Germany. ${ }^{2}$ Department of Clinical Gerontology, Robert-Bosch-Hospital, Auerbachstr. 110, 70376 Stuttgart, Germany.

Received: 21 August 2020 Accepted: 22 October 2020 Published online: 31 October 2020

\section{References}

1. ADI - Alzheimer's Disease International. World Alzheimer report 2013: An analysis of long-term care for dementia. London; 2013.

2. Long-term care resources and utilisation. [cited 05 November 2018]. Available from: https://doi.org/10.1787/data-00543-en.

3. Federal Ministry of Health [Bundesministerium fuer Gesundheit]. Long-term care insurance - facts and figures2018 5 November 2018. Available from: https://www.bundesgesundheitsministerium.de/themen/pflege/ pflegeversicherung-zahlen-und-fakten.html.

4. Costa-Font J. Family ties and the crowding out of long-term care insurance. Oxf Rev Econ Policy. 2010;26(4):691-712.

5. Stancanelli E. Institutional long-term care and government regulation. IZA World Labor. 2015

6. Palese A, Menegazzi G, Tullio A, Zigotti Fuso M, Hayter M, Watson R. Functional decline in residents living in nursing homes: a systematic review of the literature. J Am Med Dir Assoc. 2016;17(8):694-705.

7. Häcker J, Hackmann T. Los (T) in long-term care: empirical evidence from German data 2000-2009. Health Econ. 2012:21:1427-43.

8. Hellström $\mathrm{H}$, Hallberg I. Perspectives of elderly people receiving home help on health, care and quality of life. Health Soc Care Community. 2008:9(2):61-71.

9. Bowman C, Whistler J, Ellerby M. A national census of care home residents. Age Ageing. 2004;33(6):561-6.

10. Rapp K, Lamb SE, Klenk J, Kleiner A, Heinrich S, Konig HH, et al. Fractures after nursing home admission: incidence and potential consequences. Osteoporos Int. 2009;20(10):1775-83.

11. Francesca C, Ana L-N, Jérôme M, Frits T. OECD health policy studies help wanted? Providing and paying for long-term care: providing and paying for long-term care: OECD Publishing; 2011.

12. Mennicken $\mathrm{R}$, Augurzky $\mathrm{B}$, Rothgang $\mathrm{H}$, Wasem J. Explaining differences in remuneration rates of nursing homes in Germany. Eur J Health Econ. 2014; 15:401.

13. De la Maisonneuve C, Martins JO. A projection method for public health and long-term care expenditures, OECD Economics Department Working Papers; 2013. p. 1048.

14. Alders $\mathrm{P}$, Costa-Font J, de Klerk M, Frank R. What is the impact of policy differences on nursing home utilization? The cases of Germany and the Netherlands. Health Policy. 2015;119(6):814-20.

15. Health expenditure and financing: Health expenditure indicators. [cited 05 November 2018]. Available from: https://doi.org/10.1787/data-00349-en.

16. Dale MC, Burns A, Panter L, Morris J. Factors affecting survival of elderly nursing home residents. Int J Geriatr Psychiatry. 2001;16(1):70-6.

17. Van Dijk P, Mehr DR, Ooms ME, Madsen R, Petroski G, Frijters DH, et al. Comorbidity and 1-year mortality risks in nursing home residents. J Am Geriatr Soc. 2005;53(4):660-5

18. Schulz E. The long-term care system in Germany: DIW Berlin, German Institute for Economic Research; 2010

19. Rapp K, Rothenbacher D, Magaziner J, Becker C, Benzinger P, König H-H, et al. Risk of nursing home admission after femoral fracture compared with stroke, myocardial infarction, and pneumonia. J Am Med Dir Assoc. 2015;16: 715. e7-e12.
20. Koller MT, Raatz H, Steyerberg EW, Wolbers M. Competing risks and the clinical community: irrelevance or ignorance? Stat Med. 2012;31(11-12):1089-97.

21. Noordzij M, Leffondré K, van Stralen KJ, Zoccali C, Dekker FW, Jager KJ. When do we need competing risks methods for survival analysis in nephrology? Nephrol Dial Transplant. 2013;28(11):2670-7.

22. Lau B, Cole SR, Gange SJ. Competing risk regression models for epidemiologic data. Am J Epidemiol. 2009;170:244-56.

23. Wolbers M, Koller MT, Witteman JC, Steyerberg EW. Prognostic models with competing risks: methods and application to coronary risk prediction. Epidemiology. 2009;20(4):555-61.

24. Boyd CM, Xue QL, Simpson CF, Guralnik JM, Fried LP. Frailty, hospitalization, and progression of disability in a cohort of disabled older women. Am J Med. 2005;118(11):1225-31.

25. Sager MA, Rudberg MA. Functional decline associated with hospitalization for acute illness. Clin Geriatr Med. 1998;14(4):669-79.

26. Charlson ME, Pompei P, Ales KL, MacKenzie CR. A new method of classifying prognostic comorbidity in longitudinal studies: development and validation. J Chronic Dis. 1987;40(5):373-83.

27. Elixhauser A, Steiner C, Harris DR, Coffey RM. Comorbidity measures for use with administrative data. Med Care. 1998;36(1):8-27.

28. Gagne JJ, Glynn RJ, Avorn J, Levin R, Schneeweiss S. A combined comorbidity score predicted mortality in elderly patients better than existing scores. J Clin Epidemiol. 2011;64(7):749-59.

29. Fine JP, Gray RJ. A proportional hazards model for the subdistribution of a competing risk. J Am Stat Assoc. 1999;94(446):496-509.

30. Royall R. The effect of sample size on the meaning of significance tests. Am Stat. 1986;40:313-5.

31. Kohl M, Plischke M, Leffondré K, Heinze G. PSHREG: a SAS macro for proportional and nonproportional subdistribution hazards regression. Comput Methods Prog Biomed. 2015;118(2):218-33.

32. Flacker JM, Kiely DK. A practical approach to identifying mortality-related factors in established long-term care residents. J Am Geriatr Soc. 1998:46(8):1012-5.

33. Flacker JM, Kiely DK. Mortality-related factors and 1-year survival in nursing home residents. J Am Geriatr Soc. 2003;51(2):213-21.

34. Lunney JR, Lynn J, Foley DJ, Lipson S, Guralnik JM. Patterns of functional decline at the end of life. JAMA. 2003:289(18):2387-92

35. Gill TM, Gahbauer EA, Han L, Allore HG. Trajectories of disability in the last year of life. N Engl J Med. 2010;362(13):1173-80.

36. Yeh K-P, Lin M-H, Liu L-K, Chen L-Y, Peng L-N, Chen L-K. Functional decline and mortality in long-term care settings: static and dynamic approach. J Clin Gerontol Geriatr. 2014;5(1):13-7.

37. Van der Steen JT, Mehr DR, Kruse RL, Ribbe MW, van der Wal G. Treatment strategy and risk of functional decline and mortality after nursing-home acquired lower respiratory tract infection: two prospective studies in residents with dementia. Int J Geriatr Psychiatry. 2007;22(10):1013-9.

38. Carpenter Gl, Hastie CL, Morris JN, Fries BE, Ankri J. Measuring change in activities of daily living in nursing home residents with moderate to severe cognitive impairment. BMC Geriatr. 2006;6(1):7.

39. Caljouw MA, Cools HJ, Gussekloo J. Natural course of care dependency in residents of long-term care facilities: prospective follow-up study. BMC Geriatr. 2014;14(1):67.

40. Schüssler S, Dassen T, Lohrmann C. Care dependency and nursing care problems in nursing home residents with and without dementia: a crosssectional study. Aging Clin Exp Res. 2016;28(5):973-82.

41. Helvik A-S, Engedal K, Benth JŠ, Selbæk G. A 52 month follow-up of functional decline in nursing home residents-degree of dementia contributes. BMC Geriatr. 2014;14(1):45.

42. Magaziner J, Zimmerman S, Gruber-Baldini AL, van Doorn C, Hebel JR, German P, et al. Mortality and adverse health events in newly admitted nursing home residents with and without dementia. J Am Geriatr Soc. 2005; 53(11):1858-66.

43. Williams MM, Xiong C, Morris JC, Galvin JE. Survival and mortality differences between dementia with Lewy bodies vs Alzheimer disease. Neurology. 2006:67(11):1935-41.

44. Cereda E, Pedrolli C, Zagami A, Vanotti A, Piffer S, Faliva M, et al. Alzheimer's disease and mortality in traditional long-term care facilities. Arch Gerontol Geriatr. 2013;56(3):437-41.

45. Hébert R, Dubois M-F, Wolfson C, Chambers L, Cohen C. Factors associated with long-term institutionalization of older people with dementia: data from the Canadian study of health and aging. J Gerontol A Biol Sci Med Sci. 2001;56(11):M693-M9. 
46. Scott WK, Edwards KB, Davis DR, Cornman CB, Macera CA. Risk of institutionalization among community long-term care clients with dementia. Gerontologist. 1997;37(1):46-51.

47. Wirth R, Streicher M, Smoliner C, Kolb C, Hiesmayr M, Thiem U, et al. The impact of weight loss and low BMl on mortality of nursing home residents results from the nutritionDay in nursing homes. Clin Nutr. 2016;35(4):900-6.

48. Sullivan D, Morley J, Johnson L, Barber A, Olson J, Stevens M, et al. The GAIN (geriatric anorexia nutrition) registry: the impact of appetite and weight on mortality in a long-term care population. J Nutr Health Aging. 2002;6(4):275-81.

49. Kiely DK, Flacker JM. Resident characteristics associated with mortality in long-term care nursing homes: is there a gender difference? J Am Med Dir Assoc. 2000;1(1):8-13.

50. Tinetti ME, McAvay GJ, Chang SS, Newman AB, Fitzpatrick AL, Fried TR, et al. Contribution of multiple chronic conditions to universal health outcomes. J Am Geriatr Soc. 2011;59(9):1686-91.

51. Fried LP, Guralnik JM. Disability in older adults: evidence regarding significance, etiology, and risk. J Am Geriatr Soc. 1997;45(1):92-100.

52. Berry SD, Ngo L, Samelson EJ, Kiel DP. Competing risk of death: an important consideration in studies of older adults. J Am Geriatr Soc. 2010; 58(4):783-7.

53. Austin $P C$, Lee DS, Fine JP. Introduction to the analysis of survival data in the presence of competing risks. Circulation. 2016;133(6):601-9.

54. Austin PC, Fine JP. Practical recommendations for reporting Fine-Gray model analyses for competing risk data. Stat Med. 2017;36(27):4391-400.

\section{Publisher's Note}

Springer Nature remains neutral with regard to jurisdictional claims in published maps and institutional affiliations.

Ready to submit your research? Choose BMC and benefit from:

- fast, convenient online submission

- thorough peer review by experienced researchers in your field

- rapid publication on acceptance

- support for research data, including large and complex data types

- gold Open Access which fosters wider collaboration and increased citations

- maximum visibility for your research: over $100 \mathrm{M}$ website views per year

At BMC, research is always in progress.

Learn more biomedcentral.com/submissions 